\title{
Temporomandibular Joint Condylar Changes Following Maxillomandibular Advancement and Articular Disc Repositioning
}

\author{
Joao Roberto Goncalves, DDS, PhD*, Larry Miller Wolford, $\mathrm{DMD}^{\dagger}$, Daniel Serra Cassano, \\ DDS $\ddagger$, Guilherme da Porciuncula, DDS§, Beatriz Paniagua, PhD", and Lucia Helena \\ Cevidanes, DDS, PhDI \\ *Department of Pediatric Dentistry, Faculdade de Odontologia de Araraquara, Universidade \\ Estadual Paulista, Araraquara, Brazil \\ tDepartment of Oral and Maxillofacial Surgery, Texas A\&M University Health Science Center, \\ Baylor College of Dentistry, Baylor University Medical Center, Dallas, TX \\ $\ddagger$ Department of Pediatric Dentistry, Faculdade de Odontologia de Araraquara, Universidade \\ Estadual Paulista, Araraquara, Brazil \\ §Department of Pediatric Dentistry, Faculdade de Odontologia de Araraquara, Universidade \\ Estadual Paulista, Araraquara, Brazil \\ "University of North Carolina at Chapel Hill, Chapel Hill, NC \\ IUniversity of Michigan, Ann Arbor, MI
}

\section{Abstract}

Purpose-To evaluate condylar changes 1 year after bimaxillary surgical advancement with or without articular disc repositioning using longitudinal quantitative measurements in 3-dimensional (3D) temporomandibular joint (TMJ) models.

\begin{abstract}
Methods-Twenty-seven patients treated with maxillomandibular advancement (MMA) underwent cone-beam computed tomography before surgery immediately after surgery and at 1year follow-up. All patients underwent magnetic resonance imaging before surgery to assess disc displacements. Ten patients without disc displacement received MMA only. Seventeen patients with articular disc displacement received MMA with simultaneous TMJ disc repositioning (MMA-Drep). Pre- and postsurgical 3D models were superimposed using a voxel-based registration on the cranial base.
\end{abstract}

Results-The location, direction, and magnitude of condylar changes were displayed and quantified by graphic semitransparent overlays and 3D color-coded surface distance maps. Rotational condylar displacements were similar in the 2 groups. Immediately after surgery, condylar translational displacements of at least $1.5 \mathrm{~mm}$ occurred in a posterior, superior, or mediolateral direction in patients treated with MMA, whereas patients treated with MMA-Drep 
presented more marked anterior, inferior, and mediolateral condylar displacements. One year after surgery, more than half the patients in the 2 groups presented condylar resorptive changes of at least $1.5 \mathrm{~mm}$. Patients treated with MMA-Drep presented condylar bone apposition of at least 1.5 $\mathrm{mm}$ at the superior surface in $26.4 \%$, the anterior surface in $23.4 \%$, the posterior surface in $29.4 \%$, the medial surface in $5.9 \%$, or the lateral surface in $38.2 \%$, whereas bone apposition was not observed in patients treated with MMA.

Conclusions-One year after surgery, condylar resorptive changes greater than $1.5 \mathrm{~mm}$ were observed in the 2 groups. Articular disc repositioning facilitated bone apposition in localized condylar regions in patients treated with MMA-Drep.

Although mandibular advancement surgery for patients with short or normal anterior facial height has been described as the most stable among orthognathic surgeries, the stability of mandibular advancement surgery is less predictable for patients with a long-face pattern (high occlusal plane angle facial morphology). ${ }^{1,2}$ Degenerative condylar changes after mandibular or bimaxillary surgical advancement are problematic outcomes that may lead to occlusal changes after surgery and to the development or worsening of temporomandibular joint (TMJ) clinical signs and symptoms. The current literature regarding treatment effectiveness and options for the prevention of degenerative condylar changes after bimaxillary surgical advancement is controversial.

Patients with Class II long face often seek orthognathic surgery in adulthood despite a history of orthodontic and growth modification treatments during childhood. Predominantly downward and backward mandibular growth with a steep mandibular plane, short ramus vertical height, and anteroposterior mandibular deficiency have been associated with a greater susceptibility to TMJ internal derangements ${ }^{3-13}$ regardless of orthognathic surgical treatment. Changes in condylar position and TMJ loading during surgical maxillomandibular advancement (MMA) have been associated with postsurgical condylar remodeling, resorption, and instability of the surgical correction, ${ }^{14-16}$ particularly in young female patients. ${ }^{17,18}$ Hormonal imbalances and the use of oral contraceptives also have been considered potential etiologic factors for condylar resorption. ${ }^{19,20}$ A history of untreated TMJ arthritic changes (disc displacements or osteoarthritis) has been associated with poor outcomes of surgical MMA, in which further condylar arthritic changes may lead to instability after surgery. ${ }^{14,21-23}$ Among alternative treatment options, simultaneous articular disc repositioning has been advocated to avoid condylar resorption and improve stability. $22,24,25$

Quantitative 3-dimensional (3D) imaging techniques to assess and monitor the TMJ and orthognathic surgery are available. ${ }^{26-34}$ Previous studies on open joint TMJ articular disc repositioning to manage condylar arthritic changes have been limited to 2-dimensional (2D) radiographs, tomograms, or measurements of cross-sectional slices on cone-beam computed tomographic scans (CBCT). The methodology of those studies has been susceptible to errors in determining corresponding landmark positions when bone remodeling or resorption occurs, and longitudinal studies have lacked a common registration of the 3D Cartesian coordinate system. Among the achievements of the National Alliance for Medical Image Computing (http://www.na-mic.org) is free open-source image analysis software adapted 
and validated for the diagnosis and monitoring of longitudinal treatment of the maxillofacial complex and the TMJ.

The aim of this study was to investigate whether simultaneous articular disc repositioning and bimaxillary surgical advancement in patients with TMJ disc displacement lead to condylar morphologic or spatial changes similar to those observed in patients with no TMJ abnormalities before surgery.

\section{Materials and Methods}

The sample was comprised of all patients consecutively operated on by the same surgeon (L.M.W.) from November 2008 to August 2011 who met the inclusion criteria of this study: 1) female patients at least 15 years old and male patients at least 17 years old;2) surgical counterclockwise rotation advancement of the maxillomandibular complex; 3) patients with no TMJ abnormalities (assessed by magnetic resonance imaging [MRI] and clinical examination) and patients with TMJ disc displacement (assessed by MRI and clinical examination); 4) TMJ articular disc surgical repositioning performed concomitantly with orthognathic surgery for patients with TMJ disc displacement; and 5) a minimum follow-up of 11 months. The exclusion criteria were 1) phenotypic expression of craniofacial syndromes, 2) Class III malocclusion, 3) previous TMJ or maxillomandibular surgeries, and 4) incomplete records or unwillingness to participate in the study.

From a total sample of 243 patients, 27 met the inclusion criteria. These patients were divided into 2 groups. One group underwent MMA only and consisted of 10 patients who presented with no TMJ abnormalities. The other group had a diagnosis of TMJ arthritis and were prescribed MMA and disc repositioning to correct disc displacement (MMA-Drep) and consisted of 17 patients with TMJ disc dislocation who underwent MMA and counterclockwise rotation with internal rigid fixation (maxilla fixated with 4 bone plates fixated with 2.0-mm screws and sagittal split osteotomies fixated with 1 bone plate at the corpus region followed by 2 or 3 bicortical 2.0-mm bone screws at the retromolar region on each side). The bimaxillary advancement surgical technique included traditional Le Fort I osteotomy and bilateral sagittal split ramus osteotomies.

Open joint disc repositioning using the Mitek anchor (Mitek Products, Inc, Westwood, MA) technique, ${ }^{25}$ when performed, was performed during the same surgery. A modified endaural incision to gain access to the TMJ and the superior joint space was used. The capsular attachments were incised anteriorly beyond the articular eminence and posteriorly along the posterior wall of the fossa. The inferior joint space was entered with an incision just above the lateral pole of the condyle to minimize soft tissue detachment and maximize vascularity to the condyle. Care was used to avoid damage to the fibrocartilage and disc, because even viable discs can offer resistance to movement, which varies from case to case and is required to free the anterior, lateral, and sometimes medial ligamentous attachments. Passive repositioning of the disc over the condylar head was obtained with a doubled-size 0 Ethibond suture (Ethicon, Inc, Somerville, NJ) attached to a 5.0- $\times 1.8-\mathrm{mm}$ metallic anchor previously inserted in the posterolateral surface of the condylar head. Anchor insertion was performed with a 2.1-mm drill bit through the periosteum to maximize soft tissue 
attachment. It is not necessary to detach the disc from lateral pterygoid muscle. Discoplasty arthroplasty, and eminoplasty must be avoided, because these procedures usually create postsurgical adhesions of the disc to the fossa or condyle, contributing to degenerative joint disease. ${ }^{25} \mathrm{TMJ}$ articular discs were surgically repositioned in all cases that were diagnosed as displaced at MRI examination. In the protocol described in detail in the literature, ${ }^{25}$ only salvageable discs were elected for disc repositioning. In all situations, care was taken to avoid damage to the fibrocartilage of the fossa and condylar head and the disc, because injury to these structures can promote the formation of adhesions and degenerative changes after surgery. The anterior, lateral, and sometimes medial ligamentous attachments were freed, if needed, to permit passive repositioning of the disc over the condylar head in the sagittal or transverse direction. Lateral pterygoid muscle attachment was preserved. The hyperplasic bilaminar tissue was wedge resected, leaving a small portion of it attached to the posterior band of the disc for further soft tissue suture. With this technique, it was possible to reposition the disc in the mediolateral aspect with a customized insertion position of the mini-anchor into the condyle to optimize the vector of the artificial ligaments pulling it back in place in the sagittal and coronal aspects at the same time. It was not necessary to strip soft tissue from the posterior condyle for hole preparation; in general, the hole was drilled through the periosteum to maximize soft tissue attachment and blood supply to the condyle. The position of the anchor varied slightly from case to case according to the original disc position, but it was generally positioned 8 to $10 \mathrm{~mm}$ below the superior aspect of the condyle. ${ }^{25}$

Institutional review board approval for the study was obtained (Faculdade de Odontologia de Araraquara, CAAE 01125412.2.0000.5416). All patients signed an informed consent form for hospital admission, surgical procedures, and release of information for research purposes. Patients who did not consent to having their records or information released for research purposes were excluded from the study. All diagnostic imaging records requested and treatment decisions were based on the surgeon's opinion as the best option for a patient's diagnosis and treatment.

\section{MR Image Acquisition and Interpretation}

Presurgical MR images were obtained to assess disc displacement and joint effusion. All MRI procedures followed a common acquisition protocol that included $1.5 \mathrm{~T}$, a dual surface coil, T1 and T2 weighting, 2-mm (oblique sagittal) and 1.5-mm (oblique coronal) slice thicknesses, and a field of view that included the entire condyle in the closed-mouth and maximal incisal opening positions.

The imaging assessment criteria classified the disc diagnosis into 5 categories (normal, disc displacement with and without reduction, inconclusive, disc not visible) and joint effusion into 3 categories (none, slight effusion, frank effusion). ${ }^{35}$ MR images were evaluated by 2 experienced and calibrated doctors (L.M.W. and D.S.C.) in the field of TMJ diagnosis and surgical treatment. 


\section{CBCT Acquisition and 3D Image Analysis}

Volumetric datasets were acquired with the iCAT Cone Beam 3D Imaging System (Imaging Science International, Hatfield, PA) before surgery ( $\mathrm{t} 1$ ), immediately after surgery ( $\mathrm{t} 2$ ), and at 1-year follow-up (t3). The CBCT scanner was calibrated daily using a head phantom. Patients were seated upright, with the Frankfort plane (tragus-infraorbital rim line) parallel to the ground, and were instructed to remain still and not swallow during image acquisition. The mandible was positioned in a centric relation through bilateral manipulation of the patient's mandible by a trained surgeon (L.M.W.) at the scanner chair immediately before the scanning procedure that was performed in the same office. Special care was taken with patients who underwent chin osteoplasty at the 2 acquisition because of edema in this region. Patients were asked to have their lips relaxed. All CBCT scans were obtained with a 16- $\times 22-\mathrm{cm}$ field of view.

Dolphin 11.5 (Dolphin Imaging, Chatsworth, CA) was used to generate 2D lateral cephalograms from CBCT images in a perspective projection. Craniofacial measurements of changes from baseline to after surgery ( $\mathrm{t} 2 \mathrm{vs} \mathrm{t} 1$ ) were obtained for the 2 groups to test for differences between groups at baseline and differences between the amount of surgical maxillary and mandibular advancement.

CBCT images were resampled to isotropic voxel dimensions of $0.5 \times 0.5 \times 0.5 \mathrm{~mm}$ for the construction of virtual 3D surface models of the anatomic structures of interest using ITKSNAP (open-source software; http://www.itksnap.org). ${ }^{36}$ The authors followed a previously validated method. ${ }^{33}$

Images at $\mathrm{t} 1, \mathrm{t} 2$, and $\mathrm{t} 3$ were registered using the cranial base as a stable structure of reference that does not change over time or with surgical treatment. A fully automated voxel-wise rigid registration method was performed with IMAGINE (free open-source software; http://www.ia.unc.edu/dev/download/imagine/index.htm). This method, developed by Cevidanes et al, ${ }^{27}$ uses anatomic structures unaltered by treatment to drive the superimposition of different longitudinal scans of the same patient. The best transformation that superimposes $\mathrm{t} 1, \mathrm{t} 2$, and $\mathrm{t} 3$ images is obtained by comparing the gray-scale intensity for each voxel of the unaltered region of interest on each scan. Such a procedure prevents the reliance on observer-dependent and subjectively defined anatomic landmarks.

After the registration step, all reoriented virtual models were superimposed to quantitatively evaluate the greatest surface displacements using VAM software (Canfield Scientific, 2012, Fairfield, NJ; http://www.canfieldsci.com). This tool calculates thousands of color-coded point-to-point closest-point comparisons (surface distance in millimeters) between the 3D models, so that the difference between 2 surfaces at any location can be quantified.

For quantitative assessment of the changes between the 3D surface models, only userselected regions of interest were considered. VAM provides an area selection tool that allows the user to define a surface region of interest to measure all surface distances within that region. Intraexaminer reproducibility of the construction of surface models and quantification of changes over time ( $\mathrm{t} 1$ to $\mathrm{t} 2$ and $\mathrm{t} 2$ to $\mathrm{t} 3$ ) was tested for 10 randomly selected patients. The examiner was blinded and repeated all steps of the image analysis 
protocol 1 month apart. To quantify condylar changes immediately after surgery (t1 to t2) and at 1-year follow-up (t2 to t3), changes at 5 condylar regions were measured. These condylar regions were defined in relation to the longest axis along the mediolateral poles: anterior, posterior, lateral pole, medial pole, and upper surfaces. Displacements were measured as linear distances in millimeters and assigned positive and negative values indicating, respectively, inward (toward the inside of the surface) and outward (toward the outside of the surface) directions of changes. In this way, at the anterior condylar surface, positive values indicated anterior displacement or bone apposition, and negative values indicated posterior displacement or bone resorption. In the posterior condylar surface, positive values indicated posterior displacement or bone apposition, and negative values indicated anterior displacement or bone resorption. In the condyle superior surface, positive values indicated superior displacement or bone apposition, and negative values indicated inferior displacement or bone resorption. In the lateral pole of the condyle, positive values indicated lateral displacement or bone apposition, and negative values indicated medial displacement or bone resorption. In the medial pole of the condyle, positive values indicated medial displacement or bone apposition, and negative values indicated lateral displacement or bone resorption. Visual interpretation of the color maps and semitransparent overlays allowed the clinical interpretation of translational and rotational displacements and bone resorption or apposition (Fig 1). The translational displacements measured in millimeters at the 5 condylar regions describe displacements in the anterior, posterior, superior, inferior, lateral, and medial directions. Rotational displacements describe the coronal (roll), axial (yaw), and sagittal (pitch) planes of space. The resultant displacements of rotational changes also were measured in millimeters as linear distances (Fig 2).

\section{Statistical Analysis}

A $\kappa$ test was used at a 5\% level of significance to test MRI interexaminer repeated measurements. Two-sample $t$ test was used to test for baseline differences between groups MMA and MMA-Drep. The level of significance used was .05.

Descriptive statistics were used to report the percentage of patients with condylar changes of at least $1.5 \mathrm{~mm}$, set as a level of clinical significance. SPSS 20.0 (SPSS, Inc, Chicago, IL) was used for the analysis.

\section{Results}

\section{Mri Findings ${ }^{35}$}

The interexaminer diagnostic interpretation agreement was adequate $(\kappa>0.6) .{ }^{37}$ Any difference in interpretation was reconciled by a consensus interpretation.

All patients in the MMA group presented with a normal disc position in the closed- and open-mouth positions on T1-weighted MR images and had no signs of joint effusion on T2weighted MR images.

Articular disc diagnoses according to T1-weighted MRIs for patients in the MMA-Drep group showed that the disc was displaced in the closed-mouth position with reduction on the open-mouth images of 16 TMJs (47.1\%), the disc was displaced in the closed-mouth 
position without reduction on the open-mouth images of 12 TMJs (35.3\%), the disc position was indeterminate (not normal or markedly displaced in the closed-mouth position) in 5 TMJs (14.7\%), and the disc was not visible in 1 TMJ (2.9\%), and this finding was interpreted to indicate a deterioration of the disc, which is associated with advanced disc pathology. ${ }^{35}$ Interpretation of the T2-weighted MR images of patients in the MMA-Drep group showed that 21 TMJs (61.8\%) did not present joint effusion, 8 TMJs (23.5\%) had slight effusion (bright signal in the upper or lower joint space that conformed to the contours of the disc, fossa or articular eminence, or condyle), and 5 TMJs (14.7\%) had frank effusion (bright signal in either joint space that extended beyond the contours of the fossa or articular eminence or condyle).

\section{CBCT Image Analysis}

Demographic characteristics of the sample are listed in Table 1. Craniofacial characteristics showed a normal distribution and were assessed with 2-sample $t$ test for the null hypothesis in which differences between the $\mathrm{t} 1$ and $\mathrm{t} 2$ measurements were 0 .

Ten patients were randomly selected for the calibration study (30 right and 30 left condyles in 3D surface models). Repeated quantitative measurements at different anatomic regions were performed by 2 blinded observers (J.R.G. and G.P.), with an adequate intraclass correlation coefficient ( 0.78 to 0.99 ). Method error was insignificant for most variables (inferior limit for $95 \%$ confidence interval, $>0.8$ ). The variables row lateral pole up, row lateral pole down, and pitch up showed moderate method error (inferior limit for $95 \%$ confidence interval, 0.6 to 0.8 ). Visualization of semitransparent overlays allowed qualitative assessments of direction and location of changes, and closest-point color-coded distance maps provided the quantitative assessments of rotational and translational condylar changes.

\section{Surgical Changes}

Changes from t 1 to 2 are listed in Tables 2 and 3. Because of the short interval from t 1 to t2, only displacements and not bone remodeling were measured. For this reason, the directions of the displacements presented in Table 2 are absolute and not assigned (positive and negative) values.

Patients treated with MMA had condylar displacement greater than $1.5 \mathrm{~mm}$ in a posterior direction in $35 \%$, a superior direction in $20 \%$, a medial direction in $30 \%$, and a lateral direction in $15 \%$ (Table 2). Condylar medial or lateral pole presented rotation around the $z$ axis (roll) with medial roll in $32.5 \%$ of condyles, and rotation around the $y$ axis (yaw) with lateral yaw was noticed in $12.5 \%$ of condyles (Table 3 ).

In patients treated with MMA-Drep, greater than 1.5-mm condylar displacements were observed in an anterior direction in $32.3 \%$, a medial direction in 50\%, and an inferior direction in $52.8 \%$ (Table 2). Rotational condylar changes observed were medial roll in $36.7 \%$, upward pitch in $8.8 \%$, lateral yaw in $10.3 \%$, and medial yaw in $5.9 \%$ (Table 3 ). 


\section{Postsurgical Changes}

Changes from $t 2$ to $t 3$ are listed in Tables 3 and 4 . Because bone resorption and apposition from t 2 to 3 can occur, condylar displacements and bone remodeling are listed in Table 4 as (positive and negative) values measured at the 5 condylar regions.

One year after MMA surgery, observed changes were indicative of bone resorptive changes (range, -3.5 to $-1.5 \mathrm{~mm}$ ) in the anterior surface in $25 \%$, posterior surface in $10 \%$, medial surface in $25 \%$, and lateral surface in $25 \%$ of condyles. Negative measurements in the superior surface and visualization of semitransparency overlays showed flattening of the articular surface with bone resorption in $15 \%$ of condyles (range, -3.5 to $-1.5 \mathrm{~mm}$ ), as shown in the left condyle in Figure 3 and the right condyle in Figure 4. Superior displacements greater than $1.5 \mathrm{~mm}$ were observed in $20 \%$ of cases (range, 1.5 to $3.5 \mathrm{~mm}$ ), as shown in the right condyle in Figure 3. Rotational changes resulted in medial (10\%) and lateral $(12.5 \%)$ roll, medial $(7.5 \%)$ and lateral $(5.0 \%)$ yaw, and upward pitch in $5 \%$ of condyles (Table 3).

In patients who had surgical correction with MMA-Drep surgery, greater than 1.5-mm displacements or bone remodeling were observed in the anterior surface in $33.8 \%$ of condyles (20.5\% had positive values of surface measurements indicative of anterior displacement or bone apposition [Fig 5, left condyle] and 8.8\% had surface measurements indicative of posterior displacement or bone resorption [Fig 5, right condyle]). At the posterior surface, $47.1 \%$ of condyles had greater than 1.5 -mm changes, where $26.5 \%$ had posterior displacement or bone apposition, and $20.5 \%$ had bone resorption, often localized around the mini-anchor. Greater than $1.5-\mathrm{mm}$ changes occurred in the lateral and medial poles in $52.9 \%$ and $29.4 \%$ of condyles, respectively. Visualization of semitransparency overlays showed that negative measurements in the superior surface often were due to inferior displacement of the condyle with bone resorption in 32.3\% of condyles, as shown in the right condyle in Figure 5. Superior displacement and bone apposition greater than 1.5 $\mathrm{mm}$ were observed in $23.5 \%$ of condyles (range, 1.5 to $3.5 \mathrm{~mm}$ ), as shown in the right and left condyles in Figure 6. Lateral roll (26.5\%) and medial yaw (8.8\%) were the most frequently observed condylar rotations (Table 3).

\section{Discussion}

This is the first study to investigate 3D condylar spatial changes and bone remodeling after bimaxillary surgery with mandibular advancement and TMJ articular disc repositioning. This study sample of baseline craniofacial characteristics of increased vertical facial pattern and the large amount of mandibular advancement with counterclockwise rotation of the occlusal plane is unique. This study's findings showed different patterns of condylar bony changes after bimaxillary advancement surgery for patients with no previous TMJ pathology compared with patients with disc displacement who underwent simultaneous TMJ disc repositioning.

In the present study, a previously validated method was used to construct condylar surface models from CBCT scans, a process called segmentation. ${ }^{28}$ The initial automatic segmentation steps are followed by careful inspection of gray-level boundaries slice by slice 
in all 3 planes of space (sagittal, coronal, and axial) to correct for any errors in automatic segmentation. ${ }^{38-41}$ This method decreases possible surface defects and extends the segmentation process from a few seconds (in commercial automatic segmentations) to longer than an hour to complete a single condyle. All CBCT images were resampled to isotropic voxel dimensions of $0.5 \mathrm{~mm}$. When defining the true boundary of a condyle, the line for this boundary can cross directly through the center of a voxel or connect voxels. The selection of a voxel with 0.5-mm sides could be off by half the diagonal of the voxel (ie, $0.43 \mathrm{~mm}$ ). Because a 2-point measurement will require the selection of 2 voxels, errors in measurements in this study are estimated to be less than $0.86 \mathrm{~mm}$ owing to partial volume averaging. The present findings considered only changes greater than $1.5 \mathrm{~mm}$.

Condylar rotations immediately after surgery ( $\mathrm{t} 1$ to $\mathrm{t} 2$ ) included medial rotation through the $z$ axis (roll) in one third of patients and lateral rotation through the $y$ axis (yaw). Medial roll and lateral yaw occurred regardless of TMJ disc repositioning and at similar amounts and frequency. At 1 year after surgery ( 2 to $\mathrm{t} 3$ ), group MMA showed a similar frequency and amount of roll and yaw rotations toward the lateral and medial directions, whereas group MMA-Drep showed predominantly lateral roll and medial yaw.

The direction of condylar translations with the 2 surgical protocols was clearly different. The condyles translated backward, upward, laterally, and medially in patients treated with MMA only, whereas the condyles translated forward, downward, and medially in patients treated with MMA-Drep. Translations and bone resorption occurred in the 2 groups 1 year after surgery. Bone resorption was observed at the upper and lateral condylar surfaces in the 2 groups. Condyle anterior surface resorption was more frequent in group MMA, whereas posterior surface resorption occurred mainly in group MMA-Drep, particularly adjacent to the area of bone anchor placement (upper lateral quadrant of condylar posterior surface). This may be related to the artificial ligaments from the Mitek anchor placed inside the condyle, approximately 8 to $10 \mathrm{~mm}$ below the top of the condyle, extending to the posterior band of the articular disc, and the subsequent pressure the ligaments place against the posterior cortical bone on the condyle. Bone apposition was observed only after TMJ articular disc repositioning (group MMA-Drep), which seemed to facilitate condylar bone repair. New bone formation and repair were markedly variable 1 year after surgery and observed in all condylar surfaces except the lateral pole.

The present findings for patients in the MMA group corroborate those of previous studies showing that condylar displacements and rotations after mandibular advancement result in posterior, superior, and medial condylar angulations, as assessed with plain radiographs, ${ }^{42}$ cross-sectional CT images, ${ }^{43,44}$ and 3D volume superimpositions from CBCT images. ${ }^{26,31}$ The automated 3D analysis, with superimposition of follow-up scans in the same coordinate system in this study, avoids errors inherent to CBCT or CT assessments using crosssectional slice measurements. Three-dimensional Cartesian registration among images and superimposition of $3 \mathrm{D}$ volumes ${ }^{26}$ have shown that condylar displacement after isolated mandibular advancement (average, $6.8 \mathrm{~mm}$ ) in patients with low or normal anterior facial height marginally correlates with sagittal chin position 1 year after surgery. ${ }^{31}$ Reported condylar displacements were within $1 \mathrm{~mm}$ on average, but $24 \%$ of condyles presented changes greater than $2 \mathrm{~mm} .{ }^{31}$ The present study observed larger and more frequent condylar 
displacements in the 2 groups (Tables 2 to 4 ). These findings may be explained by the larger amount of surgical advancement in the present study (average, $12.3 \pm 3.5 \mathrm{~mm}$ in group MMA and $14.8 \pm 6.37 \mathrm{~mm}$ in group MMA-Drep) and by the baseline facial morphology with high anterior facial height that required bimaxillary surgery to achieve optimal results. In addition, although postsurgical images in the present study were acquired no later than 5 days after surgery, in other studies, ${ }^{26,31}$ postsurgical CBCT images were acquired 4 to 6 weeks after surgery (at the time of occlusal splint removal), when some postsurgical adaptations might have already occurred, minimizing the amount of condylar displacement reported.

The present study used image analysis procedures for the quantitative assessment of condylar surface changes similar to other previous longitudinal studies (3D model construction, longitudinal registration, and surface measurement with closest-point color maps). ${ }^{26,31,45-48}$ Those studies assessed the entire condyle as a unit, where displacements in opposite directions were measured as negative and positive values. When these values were averaged, they tended to be close to 0 and less significant. The present study modified the quantification procedures to allow the assessment of translation and rotation in 5 condylar regions and more clearly detect maximal and minimal changes not reported by previous methods. Because the rotational changes presented in Table 3 represent 3D linear displacements (in millimeters) that result from condylar rotations, the rotational findings in this study cannot be directly compared with angular findings in relation to a defined center of rotation.

Postsurgical changes observed from $\mathrm{t} 2$ to $\mathrm{t} 3$ showed condylar displacements and bone remodeling. As with conventional 2D or 3D cephalometrics, cranial base superimpositions of 3D CBCT images assess longitudinal displacements of the condyle in relation to the cranial fossa, but do not separate these displacements from bone remodeling.

Semitransparency overlays between different time points aided the distinction of surface bone remodeling from displacement with surgery.

The observed differences in the direction of condylar displacements in patients treated with MMA-Drep versus MMA was an expected outcome because it is necessary to open some space for the disc that is being positioned back and held in place with a Mitek minibone anchor inserted at the upper lateral region of the condyle. ${ }^{25}$ After disc repositioning, condylar translations and rotations were more predictable than those in patients with no history of TMJ pathology (group MMA). The large variability of condylar displacement observed in patients treated with MMA has been described in other studies. ${ }^{31,42-44,48,49}$ Such variability might be related to increased condylar loading, with possible condyle or disc position changes occurring shortly after surgery. These changes are induced by paramandibular soft tissue and muscular function, particularly in patients with short posterior vertical height or high anterior facial height.

The present study investigated whether TMJ disc repositioning would offer patients with previous TMJ disorders similar outcomes of bone adaptive changes and remodeling as those observed in patients with no history of TMJ disorders after maxillomandibular osteotomies and mandibular advancement. Bone apposition after surgery was not observed in patients 
treated with MMA only, whereas bone proliferation and repair in the articulating surface of the condyles were observed mostly in areas covered by the repositioned articular disc in patients treated with MMA-Drep. Bone resorption was often restricted to the bone anchor region, but also occurred in other condylar surfaces in patients treated with MMA-Drep. Progression of pre-existing arthritic conditions in these patients could explain such an increased localized resorption. In addition, the resorption could be related to the artificial ligaments from the Mitek anchor to the disc and the subsequent tension of these ligaments against the posterior cortical bone on the condyle. In patients treated with MMA, posterior and superior repositioning of the condyle and evident bone resorption were observed. At 1 year after surgery, the 2 groups showed condylar morphology with signs of osteoarthritis with flattening of the lateral pole. This study did not include measurements of depth and area extension of bony defects. Future studies using shape correspondence technology (spherical harmonic representation point distributed models) $)^{50-53}$ may further elucidate condylar osteoarthritic changes.

The findings of this study are particularly relevant because of controversies regarding articular disc repositioning with open joint surgery. ${ }^{54-59}$ The procedures pose the risk of aggravating the degenerative process if the fibrocartilage is inadvertently damaged and the sensitive surgical technique requires a wide learning curve for predictable results. The present study shows that adequately diagnosed and carefully performed TMJ disc repositioning at 1-year follow-up may offer patients with previous TMJ disorders similar outcomes of bone adaptive changes and remodeling as those observed in patients with no history of TMJ disorders. However, before such findings can influence practice decisions, the newly formed condylar bone observed in patients treated with MMA-Drep requires longterm studies to better interpret the improved overall stability reported with TMJ disc repositioning in orthognathic surgery. ${ }^{54-57}$ Long-term follow-up also will require regional superimposition and quantitative measurements, such as shape correspondence, ${ }^{28,33,58}$ for precise quantification of condylar changes.

Patients with a vertical facial pattern treated with surgical MMA showed marked condylar displacement and bone remodeling adaptive changes 1 year after surgery. Postsurgical adaptations tended to compensate for condylar displacements that occurred with surgery in the 2 groups. One year after surgery, mild condylar resorptive changes were observed in the 2 groups, although articular disc repositioning facilitated bone apposition in localized condylar regions.

\section{Acknowledgments}

This work was supported by the São Paulo Research Foundation (FAPESP; proc no 2010/20919-0).

\section{References}

1. Bailey L, Cevidanes L, Proffit W. Stability and predictability of orthognathic surgery. Am J Orthod Dentofacial Orthop. 2004; 126:273. [PubMed: 15356484]

2. Proffit WR, Turvey TA, Phillips C. The hierarchy of stability and predictability in orthognathic surgery with rigid fixation: An update and extension. Head Face Med. 2007; 3:21. [PubMed: 17470277] 
3. Bertram S, Moriggl A, Neunteufel N, et al. Lateral cephalometric analysis of mandibular morphology: Discrimination among subjects with and without temporomandibular joint disk displacement and osteoarthrosis. J Oral Rehabil. 2012; 39:93. [PubMed: 21923719]

4. Cai XY, Jin JM, Yang C. Changes in disc position, disc length, and condylar height in the temporomandibular joint with anterior disc displacement: A longitudinal retrospective magnetic resonance imaging study. J Oral Maxillofac Surg. 2011; 69:340. [PubMed: 20678840]

5. Emshoff R, Moriggl A, Rudisch A, et al. Cephalometric variables discriminate among magnetic resonance imaging-based structural characteristic groups of the temporomandibular joint. Oral Surg Oral Med Oral Pathol Oral Radiol Endod. 2011; 112:118. [PubMed: 21546280]

6. Emshoff R, Moriggl A, Rudisch A, et al. Are temporomandibular joint disk displacements without reduction and osteoarthrosis important determinants of mandibular backward positioning and clockwise rotation? Oral Surg Oral Med Oral Pathol Oral Radiol Endod. 2011; 111:435. [PubMed: 20869274]

7. Flores-Mir C, Nebbe B, Heo G, et al. Longitudinal study of temporomandibular joint disc status and craniofacial growth. Am J Orthod Dentofacial Orthop. 2006; 130:324. [PubMed: 16979490]

8. Gidarakou IK, Tallents RH, Kyrkanides S, et al. Comparison of skeletal and dental morphology in asymptomatic volunteers and symptomatic patients with bilateral degenerative joint disease. Angle Orthod. 2003; 73:71. [PubMed: 12607858]

9. Kimos P, Nebbe B, Heo G, et al. Changes in temporomandibular joint sagittal disc position over time in adolescents: A longitudinal retrospective study. Am J Orthod Dentofacial Orthop. 2009; 136:185. [PubMed: 19651347]

10. Lee DG, Kim TW, Kang SC, et al. Estrogen receptor gene polymorphism and craniofacial morphology in female TMJ osteoarthritis patients. Int J Oral Maxillofac Surg. 2006; 35:165. [PubMed: 16154319]

11. Nebbe B, Major PW, Prasad NG. Male adolescent facial pattern associated with TMJ disk displacement and reduction in disk length: Part II. Am J Orthod Dentofacial Orthop. 1999; 116:301. [PubMed: 10474102]

12. Nebbe B, Major PW, Prasad NG. Female adolescent facial pattern associated with TMJ disk displacement and reduction in disk length: Part I. Am J Orthod Dentofacial Orthop. 1999; 116:168. [PubMed: 10434090]

13. Yang IH, Moon BS, Lee SP, et al. Skeletal differences in patients with temporomandibular joint disc displacement according to sagittal jaw relationship. J Oral Maxillofac Surg. 2012; 70:349. [PubMed: 21778011]

14. You MS, Yang HJ, Hwang SJ. Postoperative functional remodeling of preoperative idiopathic condylar resorption: A case report. J Oral Maxillofac Surg. 2011; 69:1056. [PubMed: 20633972]

15. Kobayashi T, Izumi N, Kojima T, et al. Progressive condylar resorption after mandibular advancement. Br J Oral Maxillofac Surg. 2012; 176

16. Maal TJJ, de Koning MJJ, Plooij JM, et al. One year postoperative hard and soft tissue volumetric changes after a BSSO mandibular advancement. Int J Oral Maxillofac Surg. 2012; 1

17. Arnett GW, Milam SB, Gottesman L. Progressive mandibular retrusion-idiopathic condylar resorption. Part I Am J Orthod Dentofacial Orthop. 1996; 110:8.

18. Wolford LM, Cardenas L. Idiopathic condylar resorption: Diagnosis, treatment protocol, and outcomes. Am J Orthod Dentofacial Orthop. 1999; 116:667. [PubMed: 10587602]

19. Gunson MJ, Arnett GW, Formby B, et al. Oral contraceptive pill use and abnormal menstrual cycles in women with severe condylar resorption: A case for low serum 17beta-estradiol as a major factor in progressive condylar resorption. Am J Orthod Dentofacial Orthop. 2009; 136:772. [PubMed: 19962599]

20. Gunson MJ, Arnett GW, Milam SB. Pathophysiology and pharmacologic control of osseous mandibular condylar resorption. J Oral Maxillofac Surg. 2012; 70:1918. [PubMed: 22014941]

21. Wolford LM, Reiche-Fischel O, Mehra P. Changes in temporomandibular joint dysfunction after orthognathic surgery. J Oral Maxillofac Surg. 2003; 61:655. [PubMed: 12796870]

22. Gonçalves JR, Cassano DS, Wolford LM, et al. Postsurgical stability of counterclockwise maxillomandibular advancement surgery: Effect of articular disc repositioning. J Oral Maxillofac Surg. 2008; 66:724. [PubMed: 18355597] 
23. Gill DS, El Maaytah M, Naini FB. Risk factors for post-orthognathic condylar resorption: A review. World J Orthod. 2008; 9:21. [PubMed: 18426101]

24. Wolford LM. Concomitant temporomandibular joint and orthognathic surgery. J Oral Maxillofac Surg. 2003; 61:1198. [PubMed: 14586857]

25. Mehra P, Wolford LM. The Mitek mini anchor for TMJ disc repositioning: Surgical technique and results. Int J Oral Maxillofac Surg. 2001; 30:497. [PubMed: 11829231]

26. Carvalho FDAR, Cevidanes LHS, da Motta ATS, et al. Three-dimensional assessment of mandibular advancement 1 year after surgery. Am J Orthod Dentofacial Orthop. 2010; 137(suppl): 1. [PubMed: 20122410]

27. Cevidanes LHS, Bailey LJ, Tucker GR, et al. Superimposition of 3D cone-beam CT models of orthognathic surgery patients. Dentomaxillofac Radiol. 2005; 34:369. [PubMed: 16227481]

28. Cevidanes LHS, Hajati AK, Paniagua B, et al. Quantification of condylar resorption in temporomandibular joint osteoarthritis. Oral Surg Oral Med Oral Pathol Oral Radiol Endod. 2010; 110:110. [PubMed: 20382043]

29. Cevidanes LHS, Styner MA, Phillips C, et al. 3D morphometric changes 1 year after jaw surgery. IEEE Int Symp Biomed Imaging. 2007; 1332

30. Cevidanes LHS, Styner MA, Proffit WR. Image analysis and superimposition of 3-dimensional cone-beam computed tomography models. Am J Orthod Dentofacial Orthop. 2006; 129:611. [PubMed: 16679201]

31. Motta AT, Cevidanes LHS, Carvalho FAR, et al. Three-dimensional regional displacements after mandibular advancement surgery: One year of follow-up. J Oral Maxillofac Surg. 2011; 69:1447. [PubMed: 21256643]

32. Cevidanes LHS, Alhadidi A, Paniagua B, et al. Three-dimensional quantification of mandibular asymmetry through cone-beam computerized tomography. Oral Surg Oral Med Oral Pathol Oral Radiol Endod. 2011; 111:757. [PubMed: 21497527]

33. Paniagua B, Cevidanes L, Walker D, et al. Clinical application of SPHARM-PDM to quantify temporomandibular joint osteoarthritis. Comput Med Imaging Graph. 2011; 35:345. [PubMed: 21185694]

34. Paniagua B, Cevidanes L, Zhu H, et al. Outcome quantification using SPHARM-PDM toolbox in orthognathic surgery. Int J Comput Assist Radiol Surg. 2011; 6:617. [PubMed: 21161693]

35. Ahmad M, Hollender L, Anderson Q, et al. Research diagnostic criteria for temporomandibular disorders (RDC/TMD): Development of image analysis criteria and examiner reliability for image analysis. Oral Surg Oral Med Oral Pathol Oral Radiol Endod. 2009; 107:844. [PubMed: 19464658]

36. Yushkevich PA, Piven J, Hazlett HC, et al. User-guided 3D active contour segmentation of anatomical structures: Significantly improved efficiency and reliability. Neuroimage. 2006; 31:1116. [PubMed: 16545965]

37. Landis JR, Koch GG. The measurement of observer agreement for categorical data. Biometrics. 1977; 33:159. [PubMed: 843571]

38. Rueckert D, Sonoda LI, Hayes C, et al. Nonrigid registration using free-form deformations: Application to breast MR images. IEEE Trans Med Imaging. 1999; 18:712. [PubMed: 10534053]

39. Trindade A, Assis FD, Carvalho R, et al. [Automated overlay tomographic three-dimensional models in orthognathic surgery]. 2010; 39 in Portuguese.

40. Cevidanes LHC, Motta A, Proffit WR, et al. Cranial base superimposition for 3-dimensional evaluation of soft-tissue changes. Am J Orthod Dentofacial Orthop. 2010; 137(suppl):S120. [PubMed: 20381752]

41. Chapuis J, Schramm A, Pappas I, et al. A new system for computer-aided preoperative planning and intraoperative navigation during corrective jaw surgery. IEEE Trans Inf Technol Biomed. 2007; 11:274. [PubMed: 17521077]

42. Angle AD, Rebellato J, Sheats RD. Transverse displacement of the proximal segment after bilateral sagittal split osteotomy advancement and its effect on relapse. J Oral Maxillofac Surg. 2007; 65:50. [PubMed: 17174764] 
43. Harris MD, Van Sickels JE, Alder M. Factors influencing condylar position after the bilateral sagittal split osteotomy fixed with bicortical screws. J Oral Maxillofac Surg. 1999; 57:650. [PubMed: 10368087]

44. Alder ME, Deahl ST, Matteson SR, et al. Short-term changes of condylar position after sagittal split osteotomy for mandibular advancement. Oral Surg Oral Med Oral Pathol Oral Radiol Endod. 1999; 87:159. [PubMed: 10052369]

45. Cevidanes LHS, Styner MA, Phillips C, et al. 3D morphometric changes 1 year after jaw surgery. Changes. 2007; 1332

46. Kim YJ, Oh KM, Hong JS, et al. Do patients treated with bimaxillary surgery have more stable condylar positions than those who have undergone single-jaw surgery? J Oral Maxillofac Surg. 2011; 1

47. Cevidanes LHS, Bailey LJ, Tucker GR, et al. Superimposition of 3D cone-beam CT models of orthognathic surgery patients. Dentomaxillofac Radiol. 2005; 34:369. [PubMed: 16227481]

48. Kersey ML, Nebbe B, Major PW. Temporomandibular joint morphology changes with mandibular advancement surgery and rigid internal fixation: A systematic literature review. Angle Orthod. 2003; 73:79. [PubMed: 12607859]

49. de Assis, Ribeiro; Carvalho, F.; Cevidanes, LHS.; da Motta, ATS., et al. Three-dimensional assessment of mandibular advancement 1 year after surgery. Am J Orthod Dentofacial Orthop. 2010; 137:S53.e1. [PubMed: 20381760]

50. Chapuis J, Schramm A, Pappas I, et al. A new system for computer-aided preoperative planning and intraoperative navigation during corrective jaw surgery. IEEE Trans Inf Technol Biomed. 2007; 11:274. [PubMed: 17521077]

51. Paniagua B, Cevidanes L, Walker D, et al. Clinical application of SPHARM-PDM to quantify temporomandibular joint osteoarthritis. Comput Med Imaging Graph. 2011; 35:345. [PubMed: 21185694]

52. Cevidanes LHS, Hajati AK, Paniagua B, et al. Quantification of condylar resorption in temporomandibular joint osteoarthritis. Oral Surg Oral Med Oral Pathol Oral Radiol Endod. 2010; 110

53. Styner M, Oguz I, Xu S, et al. Framework for the statistical shape analysis of brain structures using SPHARM-PDM. Insight J. 2006; 242

54. Wolford LM. Concomitant temporomandibular joint and orthognathic surgery. J Oral Maxillofac Surg. 2003; 61:1198. [PubMed: 14586857]

55. Mehra P, Wolford LM. The Mitek mini anchor for TMJ disc repositioning: Surgical technique and results. Int J Oral Maxillofac Surg. 2001; 30:497. [PubMed: 11829231]

56. Wolford LM, Reiche-Fischel O, Mehra P. Changes in temporomandibular joint dysfunction after orthognathic surgery. J Oral Maxillofac Surg. 2003; 61:655. [PubMed: 12796870]

57. Gonçalves JR, Cassano DS, Wolford LM, et al. Postsurgical stability of counterclockwise maxillomandibular advancement surgery: Effect of articular disc repositioning. J Oral Maxillofac Surg. 2008; 66:724. [PubMed: 18355597]

58. Styner M, Oguz I, Xu S, et al. Framework for the statistical shape analysis of brain structures using SPHARM-PDM. Insight J. 2006; 242

59. Sidebottom AJ. Current thinking in temporomandibular joint management. Br J Oral Maxillofac Surg. 2009; 47:91. [PubMed: 19155105] 

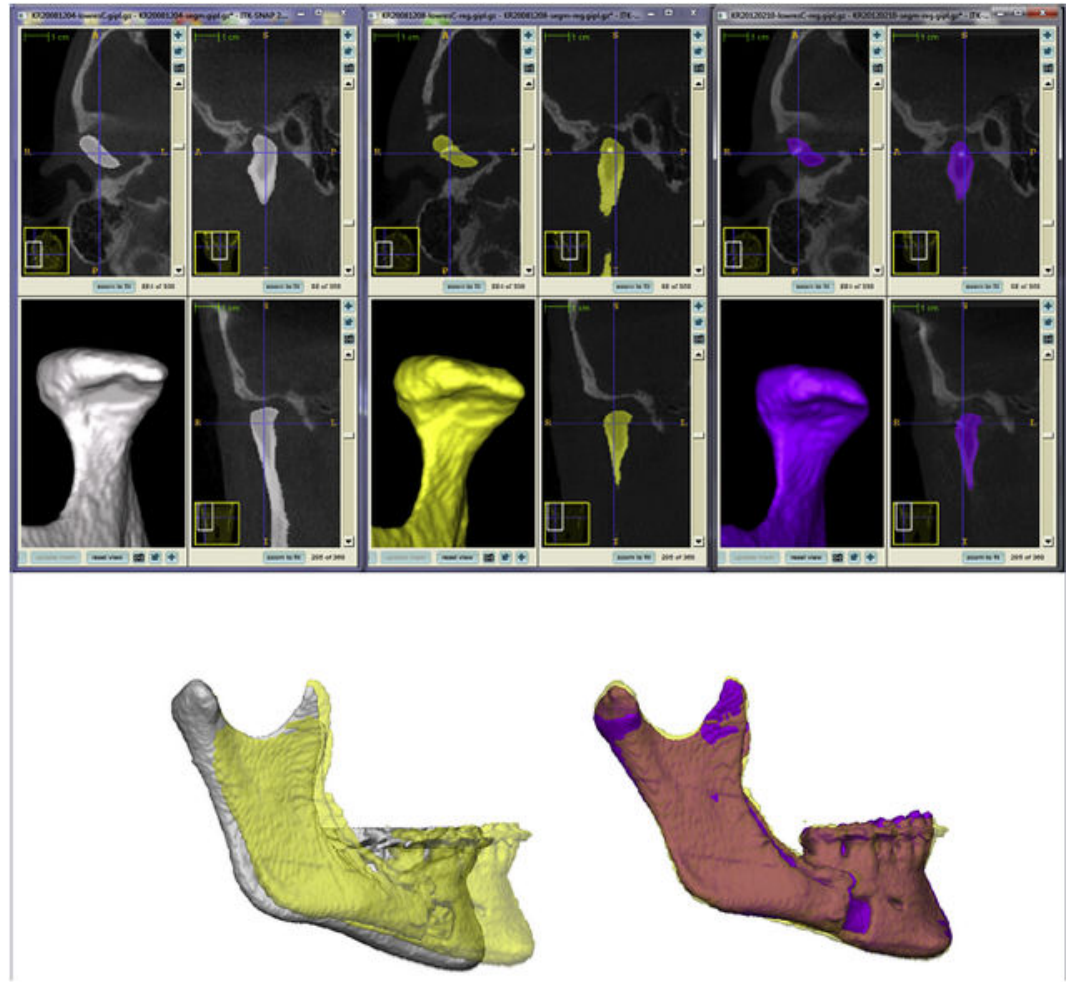

Figure 1.

Top, Three-dimensional volume and surface construction before surgery (white), immediately after surgery (yellow), and 1 year after surgery (purple) registered on the cranial base. The Mitek anchor in position is depicted immediately after and 1 year after surgery. Bottom, Overlay of mandibles registered in relation to the cranial base, with superimposition of images before surgery and immediately after surgery (right) and immediately after and 1 year after surgery (left). 


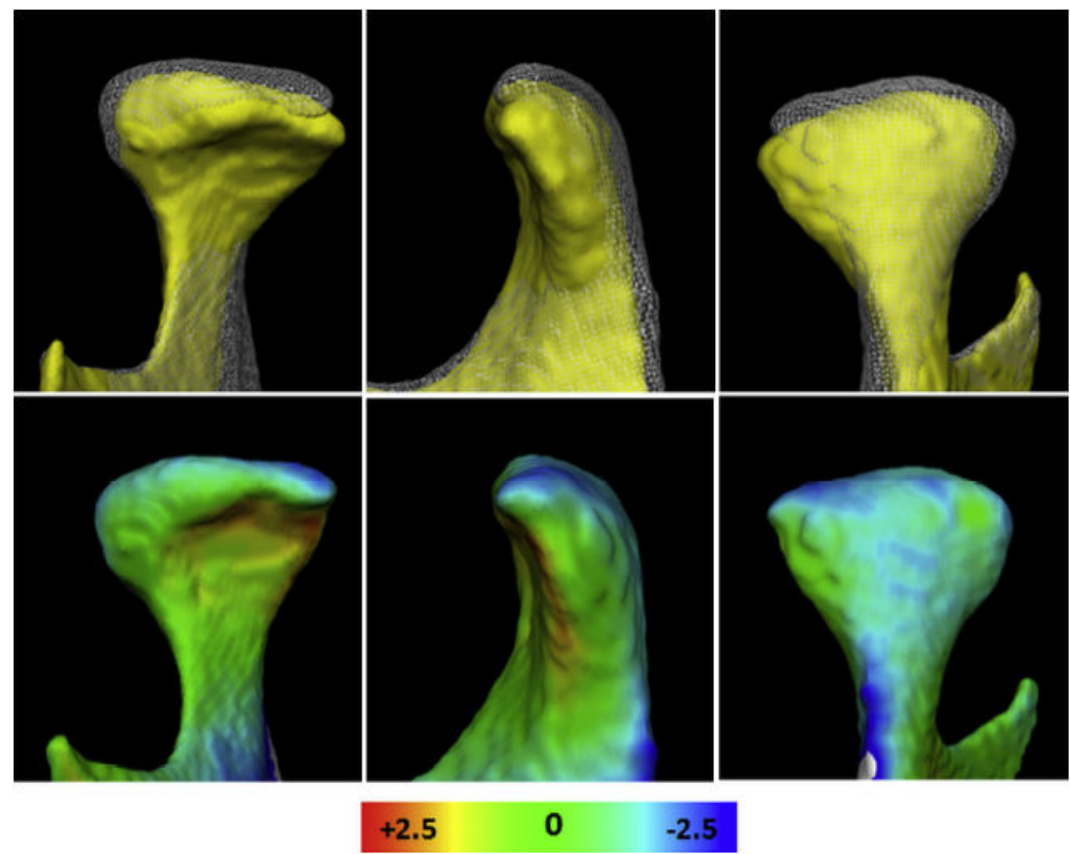

Figure 2.

Top, Wire mesh overlays of images obtained before surgery (white) and immediately after surgery (yellow). Bottom, Color-coded maps showing maximal outward (red) or inward (blue) displacement or no displacement (green) in millimeters from before surgery to immediately after surgery. 

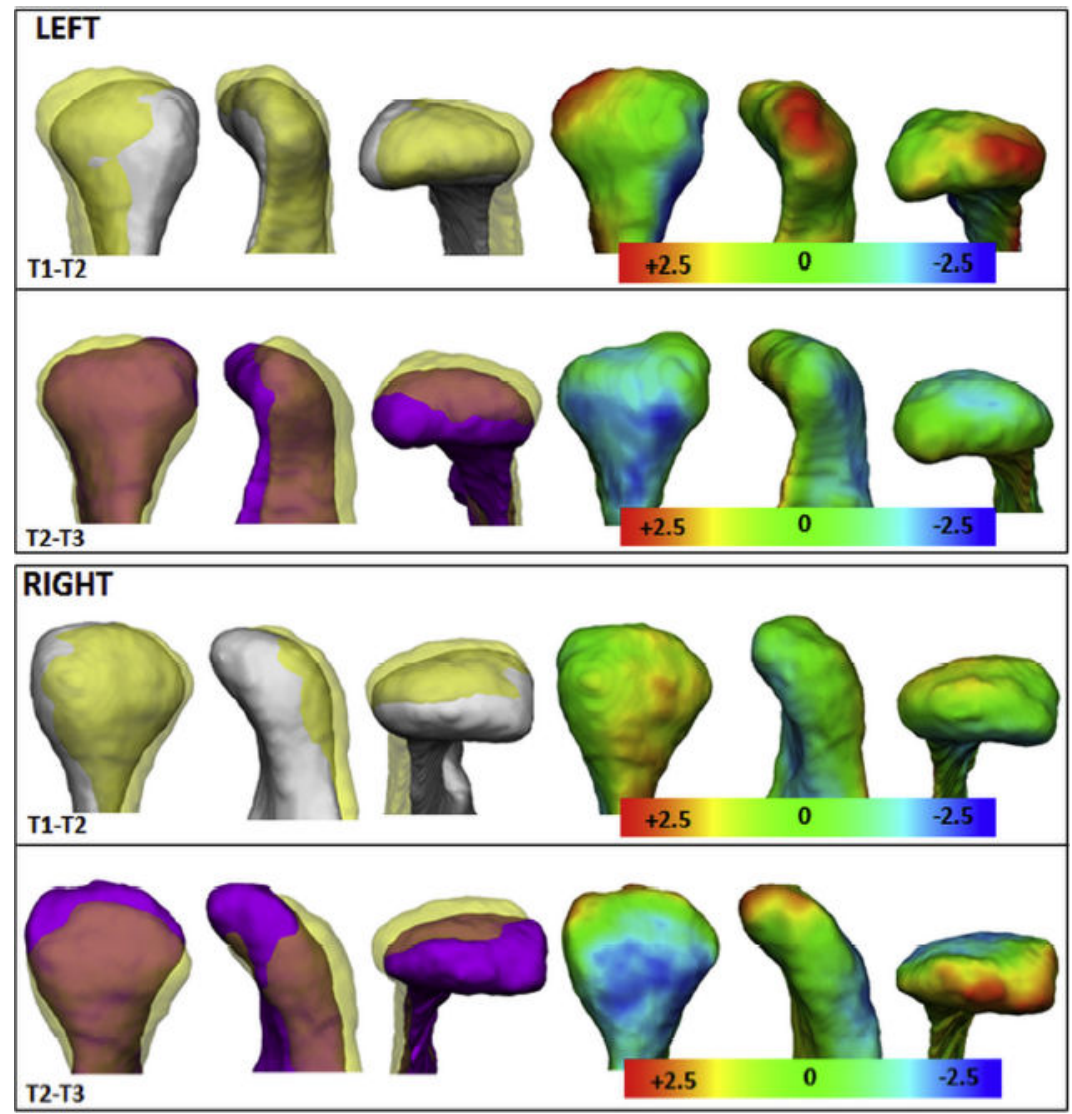

Figure 3.

Left and right condyles in patient A who underwent maxillomandibular advancement only.

Semitransparency overlays and respective color-coded closest-point distance maps of surgical (t1 to t2) and 1-year follow-up (t2 to t3) changes are shown. From right to left, Posterior, lateral (left condyle only), medial (right condyle only), and upper surfaces. Immediately after surgery ( $\mathrm{t} 1$ to $\mathrm{t} 2$ ), the left condyle exhibited superior and lateral displacement. The right condyle showed posterolateral displacement. One year after surgery ( 2 to $\mathrm{t} 3$ ), the left condyle showed bone resorption in the laterosuperior surface and anterior displacement. The right condyle exhibited medial superoanterior displacement and flattening of the posterior surface. $\mathrm{t} 1$, before surgery (white); $\mathrm{t} 2$, immediately after surgery (yellow); $\mathrm{t} 3$, 1 year after surgery (purple). 

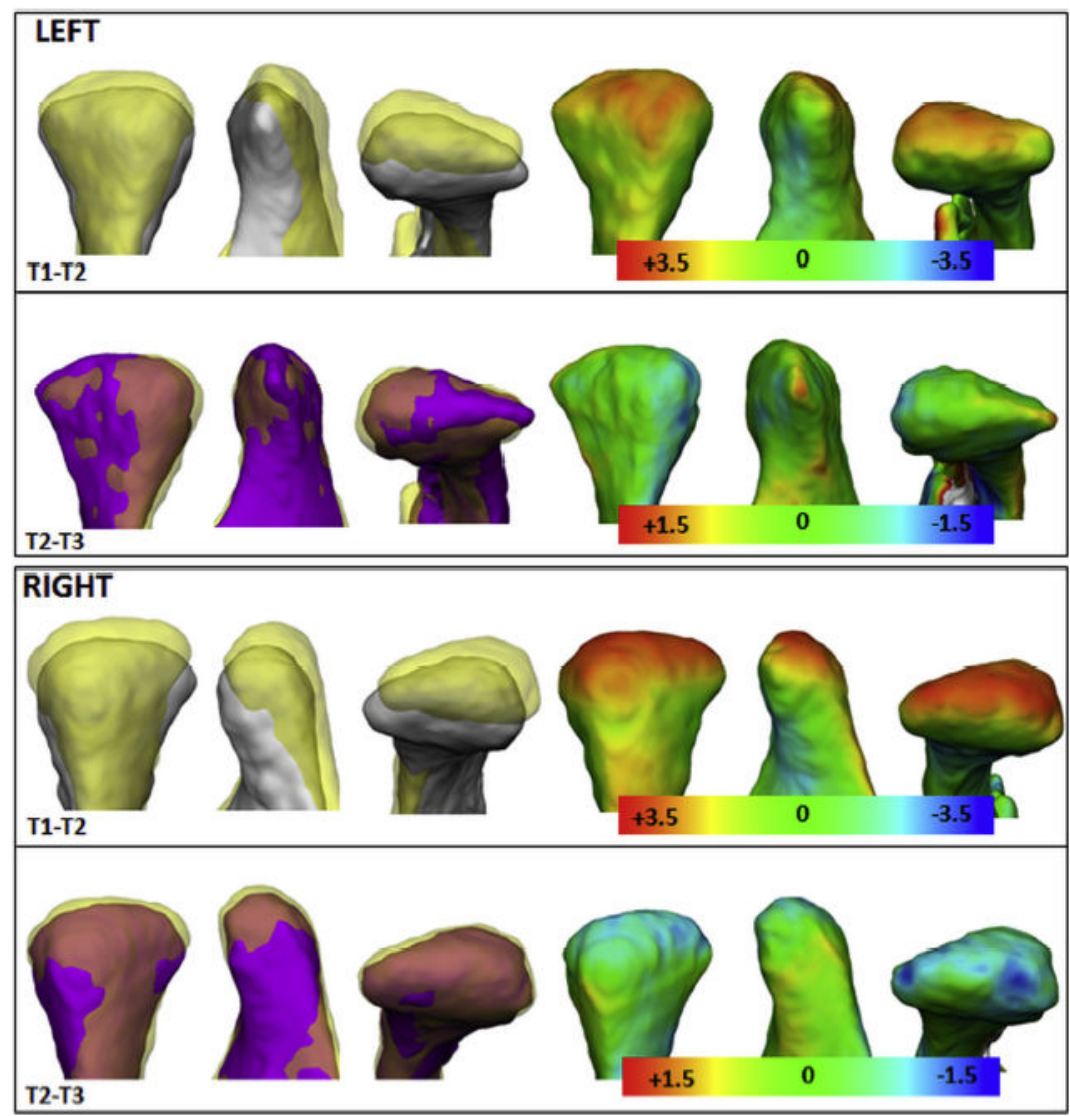

Figure 4.

Left and right condyles in patient B who underwent maxillomandibular advancement only. Semitransparency overlays and respective color-coded closest-point distance maps of surgical ( $\mathrm{t} 1$ to $\mathrm{t} 2$ ) and 1-year follow-up ( $\mathrm{t} 2$ to $\mathrm{t} 3$ ) changes are shown. Views from right to left, Posterior, lateral (left condyle only), medial (right condyle only), and upper surfaces. Immediately after surgery ( $t 1$ to $t 2$ ), the left and right condyles were displaced superiorly and posteriorly. The right condyle also showed medial roll. One year after surgery, the left condyle vertical and anteroposterior positions were maintained with a slight lateral roll. The right condyle showed overall bone resorption, appearing slightly smaller. t1, before surgery (white); $\mathrm{t} 2$, immediately after surgery (yellow); $\mathrm{t} 3,1$ year after surgery (purple). 


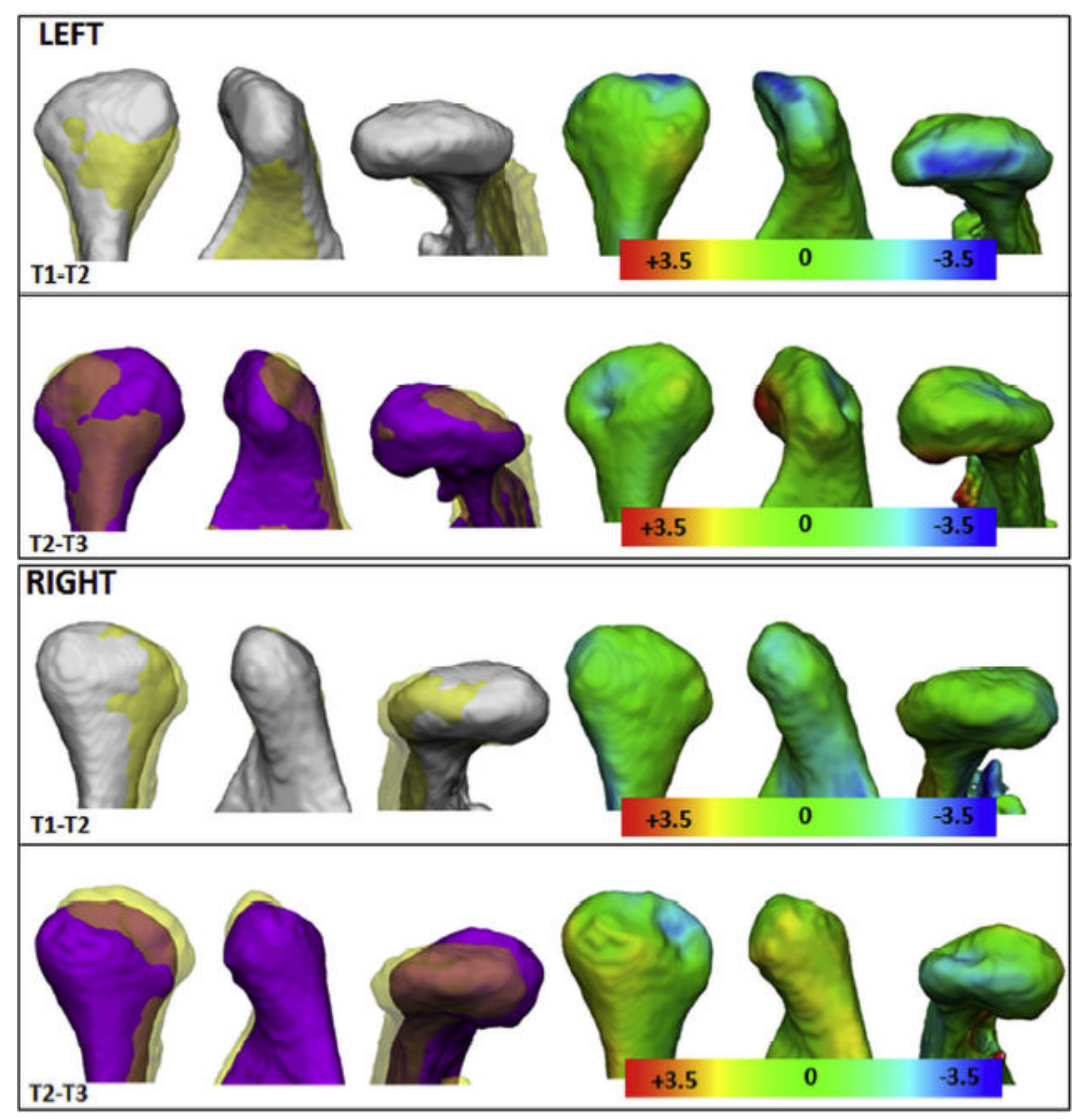

Figure 5.

Left and right condyles in patient $\mathrm{C}$ who underwent maxillomandibular advancement with simultaneous temporomandibular joint disc repositioning. Semitransparency overlays and respective color-coded closest-point distance maps of surgical (t1 to t2) and 1-year followup (t2 to t3) changes are shown. Views from right to left, Posterior, lateral (left condyle only), medial (right condyle only), and upper surfaces. Immediately after surgery (t1 to t2), the left condyle was displaced inferiorly and had a slight medial roll, whereas the right condyle was displaced laterally. One year after surgery ( 2 to $t 3$ ), inferior displacement of the left condyle was maintained with bone apposition in the anterior surface of the condyle and bone resorption around the mini-anchor (posterior surface). The right condyle tended to return to the presurgical position and had bone apposition in its medial anteroposterior surfaces. This patient showed occlusal stability 1 year after surgery. 11 , before surgery (white); $\mathrm{t} 2$, immediately after surgery (yellow); $\mathrm{t} 3,1$ year after surgery (purple). 

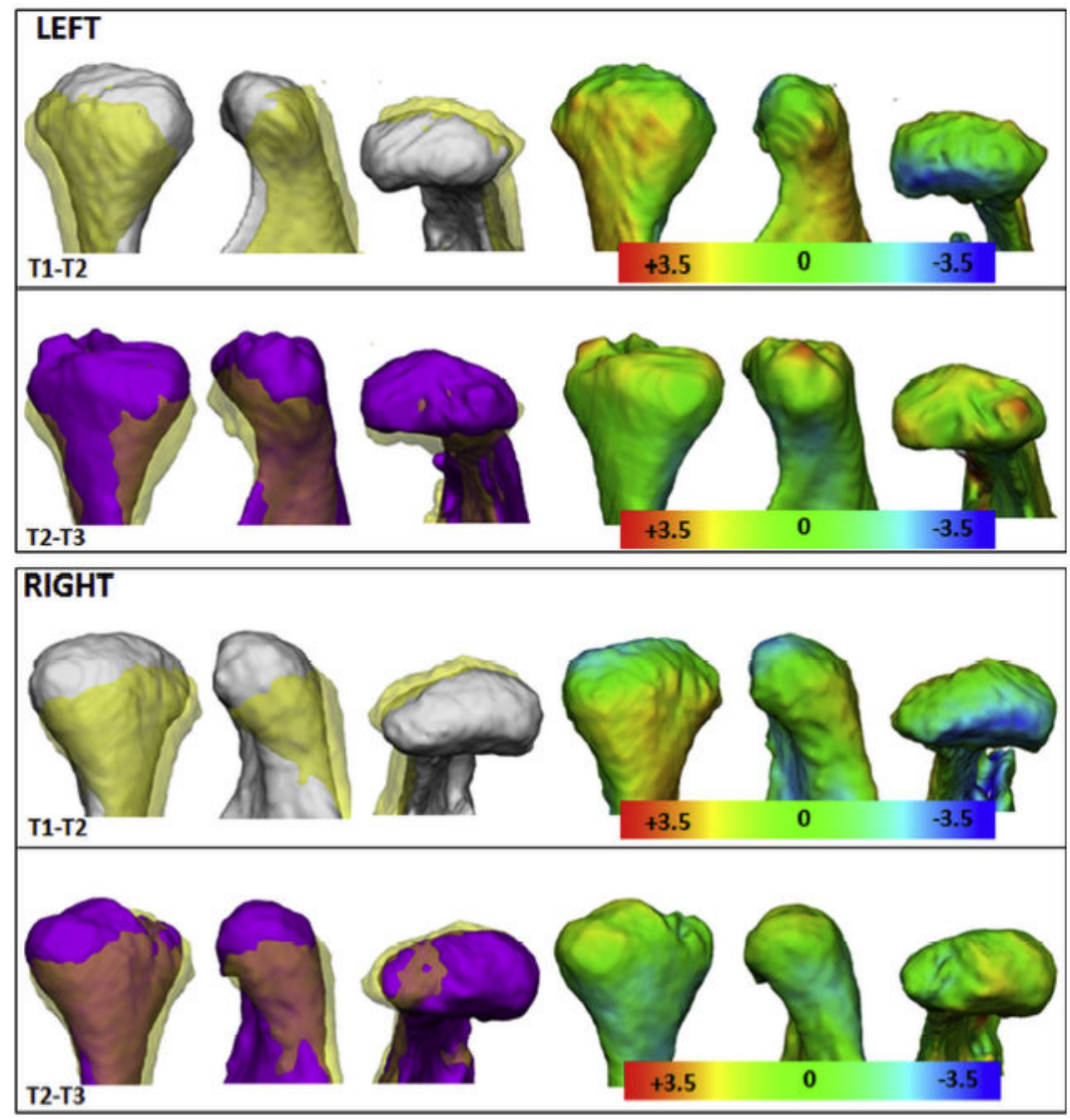

Figure 6.

Left and right condyles in patient $\mathrm{D}$ who underwent maxillomandibular advancement with simultaneous temporomandibular joint disc repositioning. Semitransparency overlays and respective color-coded closest-point distance maps of surgical (t1 to t2) and 1-year followup (t2 to t3) changes are shown. Views from right to left, Posterior, lateral (left condyle only), medial (right condyle only), and upper surfaces. Immediately after surgery (t1 to t2), the left and right condyles showed inferolateroposterior displacement and medial roll. One year after surgery ( $\mathrm{t} 2$ to $\mathrm{t} 3$ ), the right and left condyles tended to return partly to the presurgical position with irregular overall bone proliferation in the superior condylar surfaces. $\mathrm{t} 1$, before surgery (white); $\mathrm{t} 2$, immediately after surgery (yellow); $\mathrm{t} 3,1$ year after surgery (purple). 


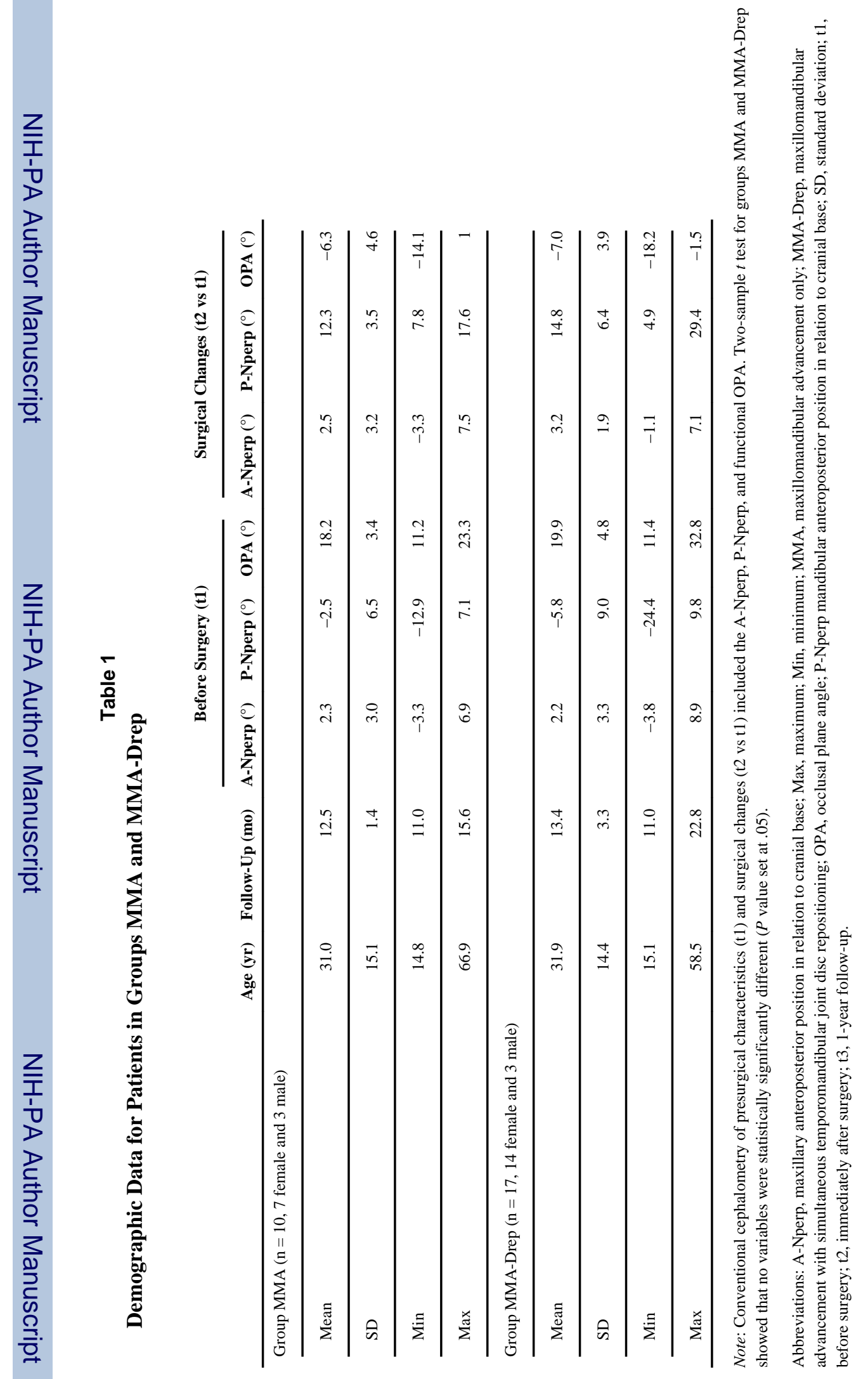


Table 2

Surgical Displacements from Before Surgery to Immediately After Surgery: Percentage of Patients with Clinical Changes in Condylar Position in Anterior, Posterior, Medial, Lateral, Superior, and Inferior Directions Greater Than 1.5 mm

\begin{tabular}{|c|c|c|c|c|}
\hline $\begin{array}{l}\text { Changes } \\
(\mathrm{mm})\end{array}$ & $\begin{array}{l}\text { Group MMA } \\
\quad(\mathbf{n}=\mathbf{2 0})\end{array}$ & $\begin{array}{l}\text { Group MMA-Drep } \\
\qquad(n=34)\end{array}$ & $\begin{array}{l}\text { Group MMA } \\
\quad(\mathbf{n}=\mathbf{2 0})\end{array}$ & $\begin{array}{c}\text { Group MMA-Drep } \\
\qquad(\mathrm{n}=\mathbf{3 4})\end{array}$ \\
\hline & Anterior & & Posterior & \\
\hline 1.5 to 3.5 & & 32.3 & 35.0 & 2.9 \\
\hline \multirow[t]{2}{*}{$\geq 3.5$} & & 2.9 & & \\
\hline & Medial & & Lateral & \\
\hline $1.5-3.5$ & 30.0 & 50.0 & 15.0 & 11.7 \\
\hline \multirow[t]{2}{*}{$\geq 3.5$} & & 2.9 & & \\
\hline & Superior & & Inferior & \\
\hline $1.5-3.5$ & 20.0 & & & 23.5 \\
\hline$\leq 3.5$ & & & & 29.3 \\
\hline
\end{tabular}

Note: Changes smaller than $1.5 \mathrm{~mm}$ are not shown.

Abbreviations: MMA, maxillomandibular advancement only; MMA-Drep, maxillomandibular advancement with simultaneous temporomandibular joint disc repositioning. 


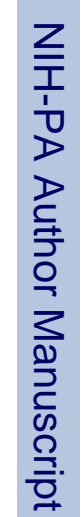

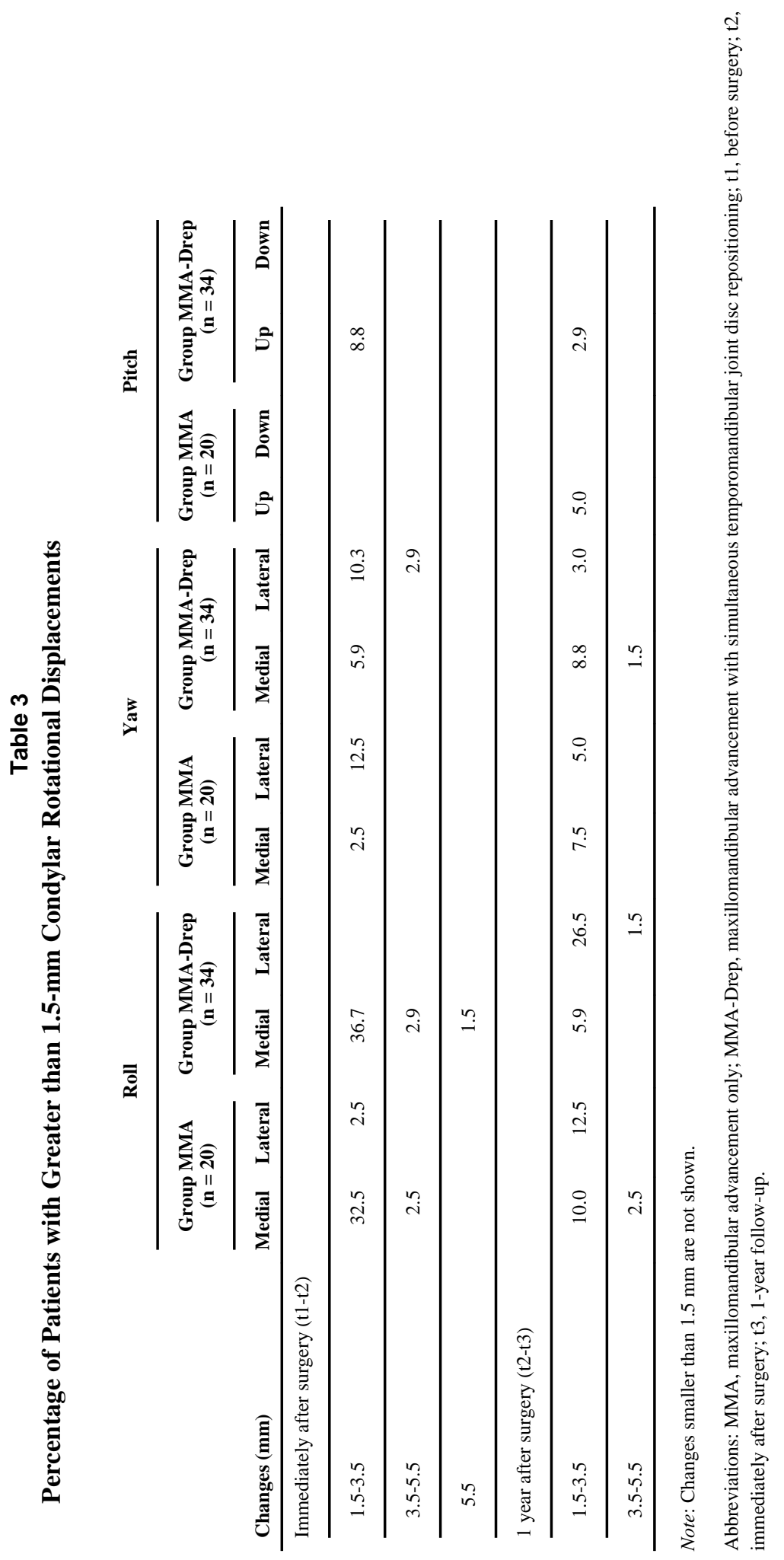

J Oral Maxillofac Surg. Author manuscript; available in PMC 2014 October 05. 
Table 4

Postsurgical Changes from Immediately After to One Year After Surgery: Percentage of Patients at One-Year Follow-up with Clinical Changes in Condylar Position and Bone Remodeling Greater than $\mathbf{1 . 5} \mathbf{~ m m}$, as Measured at Condylar Surfaces

\begin{tabular}{|c|c|c|c|c|}
\hline Changes (mm) & Group MMA (n = 20) & Group MMA-Drep $(n=34)$ & Group MMA $(\mathbf{n}=20)$ & Group MMA-Drep $(n=34)$ \\
\hline & Anterior (\%) & & Posterior $(\%)$ & \\
\hline-3.5 to -1.5 & 25.0 & 8.8 & 10.0 & 20.5 \\
\hline $1.5-3.5$ & 5.0 & 20.5 & 5.0 & 26.5 \\
\hline \multirow[t]{2}{*}{23.5} & & 2.9 & & 2.9 \\
\hline & Medial (\%) & & Lateral $(\%)$ & \\
\hline-35 to -1.5 & 25.0 & 23.5 & 25.0 & 38.2 \\
\hline $1.5-3.5$ & 5.0 & 5.9 & 5.0 & 14.7 \\
\hline \multirow[t]{2}{*}{23.5} & & & 5.0 & \\
\hline & Superior $(\%)$ & & & \\
\hline-35 to -1.5 & 15.0 & 32.3 & & \\
\hline $1.5-3.5$ & 20.0 & 23.5 & & \\
\hline 23.5 & & 2.9 & & \\
\hline
\end{tabular}

Note: Changes smaller than $1.5 \mathrm{~mm}$ are not shown. Negative $(-)$ and positive $(+)$ changes indicate direction of displacement and/or bone remodeling.

Abbreviations: MMA, maxillomandibular advancement only; MMA-Drep, maxillomandibular advancement with simultaneous temporomandibular joint disc repositioning. 